\title{
Endoscopic band ligation for nonvariceal bleeding: A review
}

\author{
Sergio Zepeda-Gómez MD ${ }^{1}$, Norman E Marcon MD FRCPC ${ }^{2}$
}

$\mathrm{E}^{\mathrm{n}}$ ndoscopic band ligation (EBL) is the most effective and accepted treatment for acute esophageal variceal bleeding (1). EBL is an easy and safe method to achieve hemostasis for gastrointestinal (GI) bleeding, in contrast to other endoscopic therapies (thermal, mechanical, injection). The use of EBL for other types of bleeding in the GI tract has been published mostly as case report series (Table 1). In the present review, we describe the results of published studies that have evaluated different options for EBL in the setting of nonvariceal bleeding.

\section{VASCULAR LESIONS IN THE GI TRACT}

Vascular malformations may cause chronic blood loss or acute GI hemorrhage. These lesions, often called angiodysplasias or vascular ectasias, are single or multiple bright red round spots of variable diameter with uniform or slightly irregular margins. These can present independently or in association with other conditions such as radiation injury, collagen vascular disease, chronic renal failure, cirrhosis or hereditary hemorrhagic telangiectasia, and they account for $1 \%$ to $5 \%$ of all causes of GI bleeding reported (2) (Figure 1).

Treatment of vascular lesions with EBL has been reported to be effective. Wong et al (3) described two patients with GI bleeding secondary to gastric angiodysplasia successfully treated with EBL, one of them previously treated with pure ethanol injection. Furthermore, Abi-Hanna et al (4) described 10 patients with vascular lesions in the stomach and duodenum successfully treated with EBL. Four of the patients had previous endoscopic therapy and four had active bleeding at the time of ligation therapy. No rebleeding was observed at a mean follow-up time of six months. In another prospective study that evaluated treatment of vascular lesions in the small bowel (5), a cohort of patients with upper GI bleeding were investigated and 14 patients with angiodysplasias were identified. These lesions were located in the duodenal bulb $(n=5)$, the second portion of the duodenum $(n=8)$ and the third portion of the duodenum $(n=1)$. All patients were treated with EBL and hemostasis was achieved in a single endoscopic session. No patients had further bleeding at 40 days of follow-up.

\section{DIEULAFOY LESION}

A Dieulafoy lesion (DL) is a large-calibre, tortuous artery that is located in the submucosa in close contact with the mucosa. The erosion of the mucosa and arterial wall can initiate massive bleeding. The majority of these lesions are located in the gastric fundus. DLs represent approximately $0.3 \%$ to $6 \%$ of all causes of GI bleeding (6).

Several reports and series on endoscopic treatment for DLs have been published. Most DLs have been treated by thermal or injection methods, or hemoclipping (7-12). The initial success rate reported for hemostasis with these methods was $84 \%$ and $90 \%$ in two different studies that included 26 and 40 patients, respectively $(7,8)$.

The first use of EBL for the treatment of a gastric DL was reported in 1994 (13). Since then, there has been a trend to treat these lesions with EBL (Figures 2 and 3). The majority of the reported cases responded immediately after one session of EBL and usually only one band per lesion was sufficient. Effective EBL of a bleeding rectal DL that was previously treated with hemoclips has also been reported (14).

Although most DLs are located in the stomach, esophageal and duodenal DLs have been successfully treated with EBL $(15,16)$.

From all the cases reviewed, we found only one case of rebleeding after $24 \mathrm{~h}$ of therapy with EBL - a shallow ulcer at the site of banding was seen and adrenaline $1: 10,000$ was injected with no further rebleeding at 12 months follow-up (4). There was only one reported case (17) of fatal rebleeding after EBL for a DL located at the gastric cardia in a patient with previous failed endoscopic treatments (injection and thermal probe coagulation). Two rubber bands had to be applied because of a large-size lesion and a delayed massive rebleeding occurred (after 33 days of EBL treatment). A diagnostic upper endoscopy was not performed, nor was an autopsy to confirm the cause of death. In a retrospective study, Mumtaz et al (18) analyzed the outcomes of patients with DL who were treated with EBL compared with thermal-injection therapy. Twenty-three patients were included in the study (14 patients in the EBL group). Active hemostasis was achieved in 100\% of cases in both groups but early rebleeding occurred in one

${ }^{1}$ Department of Gastrointestinal Endoscopy, Instituto Nacional de Ciencias Médicas y Nutrición, Mexico City, Mexico; ${ }^{2}$ The Centre for Advanced Therapeutic Endoscopy and Endoscopic Oncology, St Michael's Hospital, Toronto, Ontario

Correspondence and reprints: Dr Norman E Marcon, Division of Gastroenterology, University of Toronto, St Michael's Hospital, 30 Bond Street,

Toronto, Ontario M5B 1W8. Telephone 416-864-3092, fax 416-864-5993, e-mail norman.marcon@utoronto.ca

Received for publication July 23, 2008. Accepted August 11, 2008 
TABLE 1

Different options for endoscopic band ligation in nonvariceal bleeding

Vascular lesions in the gastrointestinal tract
Dieulafoy lesion
Mallory-Weiss tear
Gastric antral vascular ectasia
Postpolypectomy bleeding
Rubber bleb nevus syndrome
Colonic diverticular bleeding

patient in the thermal-injection therapy group. The authors concluded that EBL is as effective as injection with or without thermal therapy in the treatment of DL.

In a prospective, randomized trial (19) comparing EBL with hemoclip placement for bleeding DL, 26 patients were enrolled, 13 in each group. One rubber band was applied for each EBL case and the median number of hemoclips needed was one. Primary hemostasis was achieved in all patients with one case of rebleeding in each group. No complications were reported. The authors concluded that there were no differences in the efficacy or safety between EBL and hemoclips for the treatment of DL.

\section{MALLORY-WEISS TEAR}

Mallory-Weiss tears (MWTs) are lacerations at or near the esophagogastric junction that may cause acute GI bleeding. These lacerations are secondary to sudden elevations in abdominal pressure, usually after retching or vomiting.

The first cases of successful treatment of MWTs with EBL were reported in 1998, one after previous failed endoscopic treatment with adrenaline injection $(3,4)$.

Another patient (20) with bleeding secondary to an MWT was successfully treated with EBL. In this case, a 75-year-old man presented with hematemesis after severe retching during a gastroscopy. The bleeding stopped immediately after the release of one rubber band at the site of the mucosal tear. Gunay et al (21) reported four patients with bleeding MWTs that were successfully treated with EBL. All patients achieved complete hemostasis and no rebleeding was observed.

In a prospective, randomized trial comparing EBL with adrenaline injection for bleeding MWTs (22), 34 patients were enrolled; 17 patients underwent EBL and 17 underwent adrenaline injection. One to two rubber bands were applied in the EBL group and the mean volume of adrenaline required in the second group was $18 \mathrm{~mL}$. Primary hemostasis was achieved in all cases in the EBL group and in 16 cases in the adrenaline group, with no rebleeding or major complications in either group. The authors concluded that there was no difference in the efficacy or safety of EBL versus adrenaline injection for the treatment of bleeding MWTs. A case series also described the usefulness of EBL for bleeding MWTs (23). Thirty-seven patients were prospectively treated with EBL. Thirty-six patients achieved complete hemostasis after the first session, while the remaining patient had severe liver failure with coagulopathy. No complications were reported. The authors concluded that EBL is an effective and safe procedure for treating bleeding MWTs.

Finally, a recently published prospective, randomized study compared EBL with endoscopic hemoclip placement (EHP) in actively bleeding MWTs (24). Forty-one patients were included and 20 were treated with EBL. Primary hemostasis was achieved in all patients. Two patients in the EBL group and one in the EHP group had recurrent bleeding and were treated with a second session of the same endoscopic modality. Secondary hemostasis was achieved in all patients. There were no complications, and no differences in hospital stay or transfusion requirements between the two groups. The authors concluded that EBL and EHP are equally effective and safe for the treatment of actively bleeding MWTs.

\section{POSTPOLYPECTOMY BLEEDING}

The occurrence of bleeding after endoscopic polypectomy is seen in approximately $2 \%$ of cases, and there are several therapies to achieve hemostasis. These include hemoclips, argon plasma coagulation (APC), heater probe and adrenaline injection. The use of EBL for the treatment of postpolypectomy bleeding (PPB) in the colon was first described in 1994. Slivka et al (25) reported the case of a 70-year-old patient with multiple comorbidities and bleeding from three polypectomy stalks - two at the hepatic flexure and one at the sigmoid colon. He was treated first with electrocautery and adrenaline injection, but rebleeding occurred. EBL was performed and immediate hemostasis was observed with no further rebleeding. In another case report (26), a patient's bleeding immediately after polypectomy was controlled with EBL after unsuccessful treatment with adrenaline injection. Since then, there have been several reports of successful EBL for the treatment of PPB. One rubber band is usually required and hemostasis is achieved immediately (Figures 4 and 5). No complications of this procedure have been reported (27). No trials comparing this therapy with other modalities for PPB have been reported.

\section{GASTRIC ANTRAL VASCULAR ECTASIA}

Gastric antral vascular ectasia (GAVE) or watermelon stomach is characterized by red, angiomatous, ectatic lesions in the gastric antrum that can be associated with GI hemorrhage at endoscopic examination (28). There are two kinds of patterns identified. The first pattern is multiple red stripes, which are often raised and radiate to the pylorus. The etiology is unknown in the majority of patients but sometimes it is associated with autoimmune or connective tissue diseases. The second pattern is more diffuse lesions with a pattern of small, flat spots, primarily in the antrum. This is usually associated with portal hypertension (29).

GAVE can account for approximately $3.9 \%$ of cases of obscure GI bleeding (30). Endoscopic treatment is now the preferred therapy in the majority of cases. Surgical therapy consisting of antrectomy is effective but its application is limited by the high surgical risk of most patients and the morbidity related to the procedure.

Various endoscopic treatment modalities have been used for GAVE. These include monopolar electrocoagulation, heater probe, cryotherapy and APC (31-36). Currently, APC is the most frequent endoscopic modality used for the treatment of GAVE. The treatment time and number of sessions needed to complete eradication of lesions depends on the pattern (the diffuse type takes longer to eradicate), the extent and number of lesions, and the circumstances of treatment (active bleeding takes more sessions than elective therapy). On average, two to four treatment sessions are needed to achieve complete eradication with APC. Two recent reports have described 


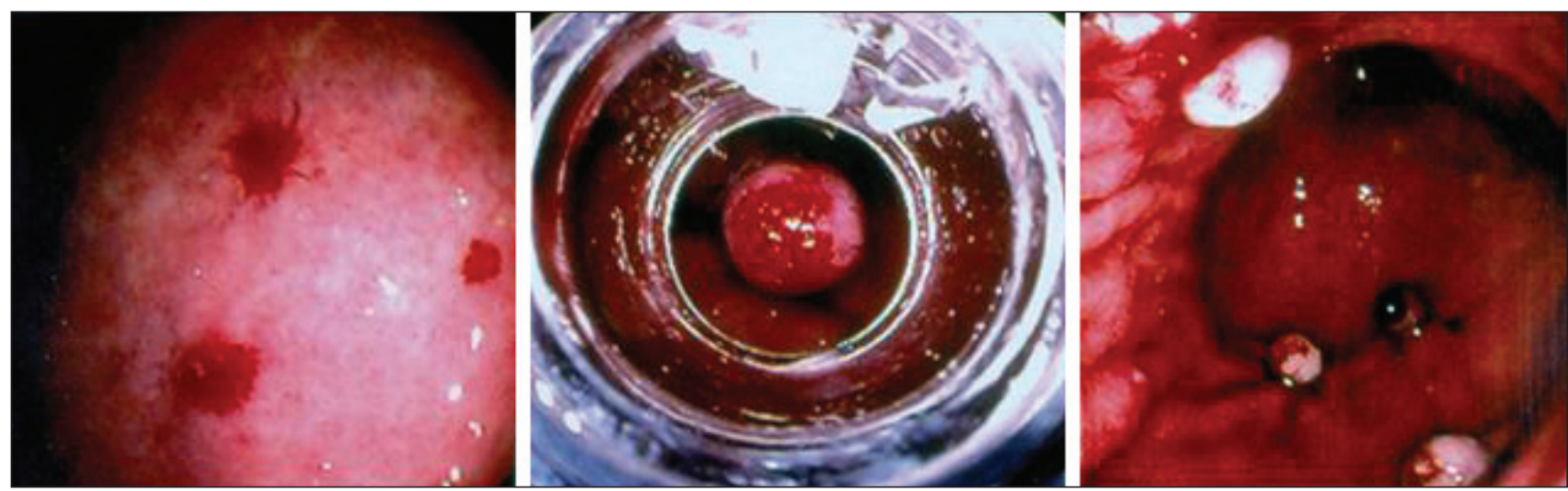

Figure 1) Multiple angiodysplasias in a patient with hereditary hemorrhagic telangiectasia. Muliple lesions were ligated
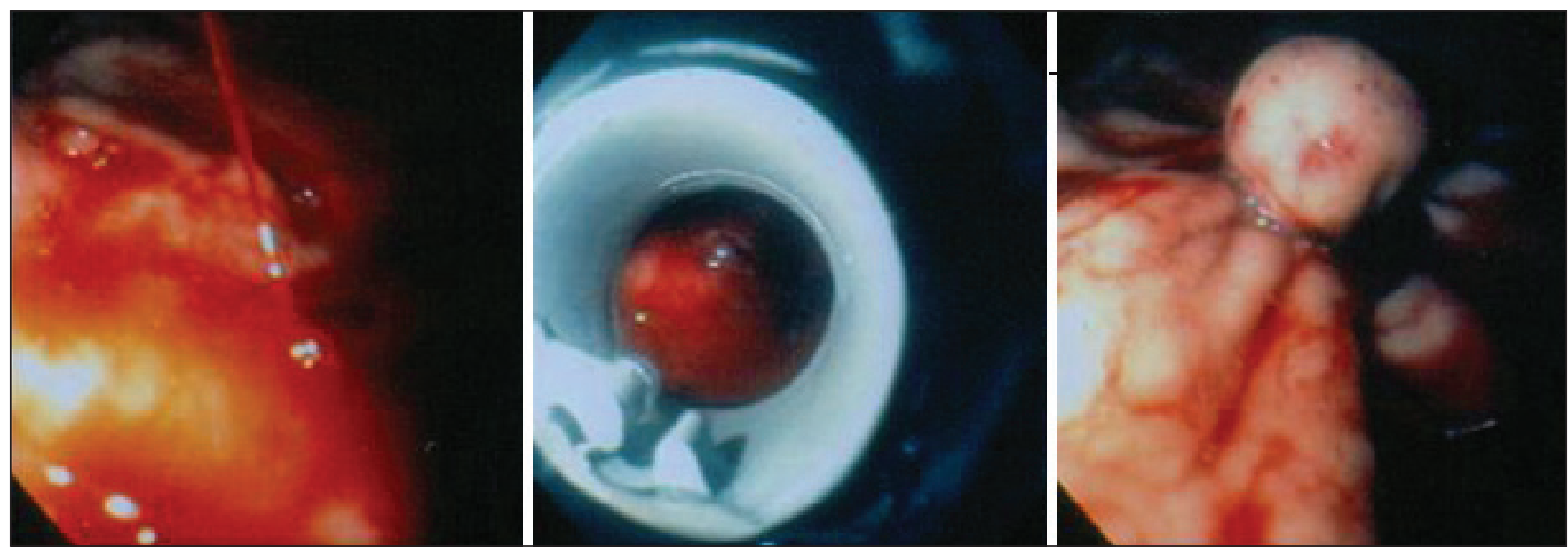

Figure 2) Spurting Dieulafoy ulcer controlled with rubber band ligation

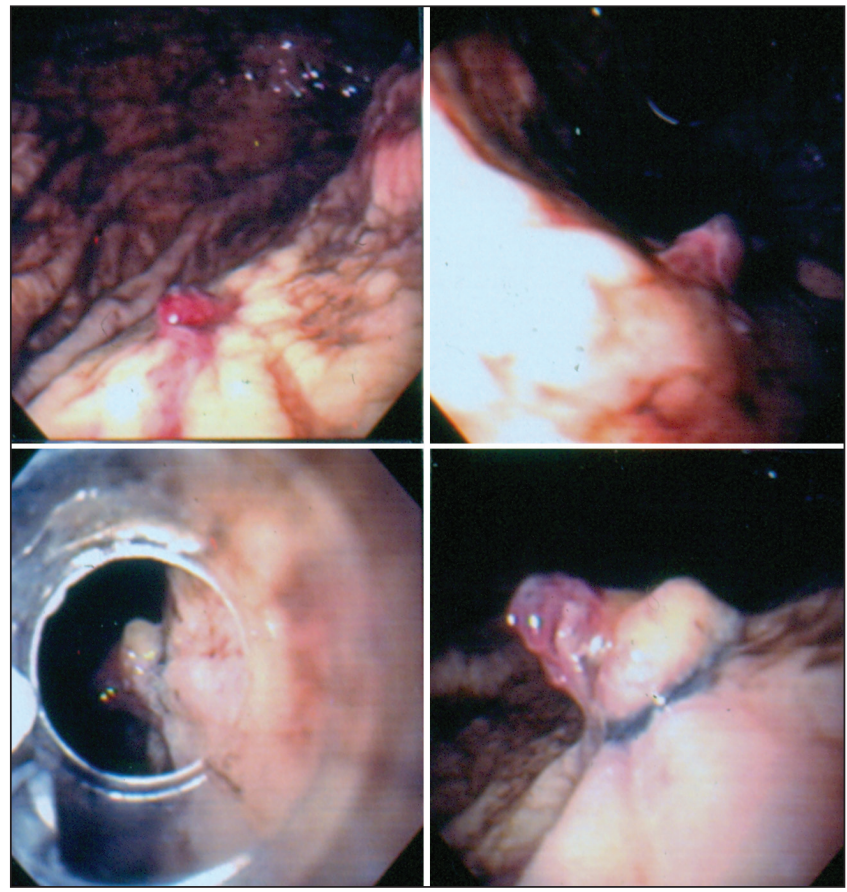

Figure 3) Nonbleeding Dieulafoy ulcer

the use of EBL for the treatment of GAVE. In the first report (37), a 53-year-old man was evaluated for iron deficiency anemia and an episode of hematemesis. An upper endoscopy revealed a type $1 \mathrm{GAVE}$, and EBL of the ectasias was performed because APC was not available. Six bands were deployed from the stripes of the pylorus to a more proximal location. Further endoscopies revealed partial resolution of the lesions and a second session of EBL was performed six months later, applying another six bands that targeted the residual areas of GAVE. No complications were observed during or after the procedure. The hemoglobin level stabilized and subsequent endoscopic examinations after two and six months showed complete resolution of GAVE. The patient remained asymptomatic after 16 months of follow-up. In another case report (38), a 55-year-old woman with a history of melena and severe anemia had been treated with APC on two occasions for GAVE. She was treated with EBL as a salvage therapy. In the first session, five bands were applied and in the second (two weeks later), 11 bands were deployed. There was clinical and endoscopic improvement, and the reported adverse effects after EBL were epigastric pain controlled by oral analgesics (not specified) and ulcers at the site of treatment, which healed completely. After 15 months of follow-up, she remained stable.

\section{OTHER CAUSES OF GI BLEEDING}

There was one report (39) of the use of EBL for rubber bleb nevus syndrome in a 15-year-old boy with hematemesis and four elevated bluish lesions in the antrum. Two treatment sessions were performed and no further bleeding was documented. 


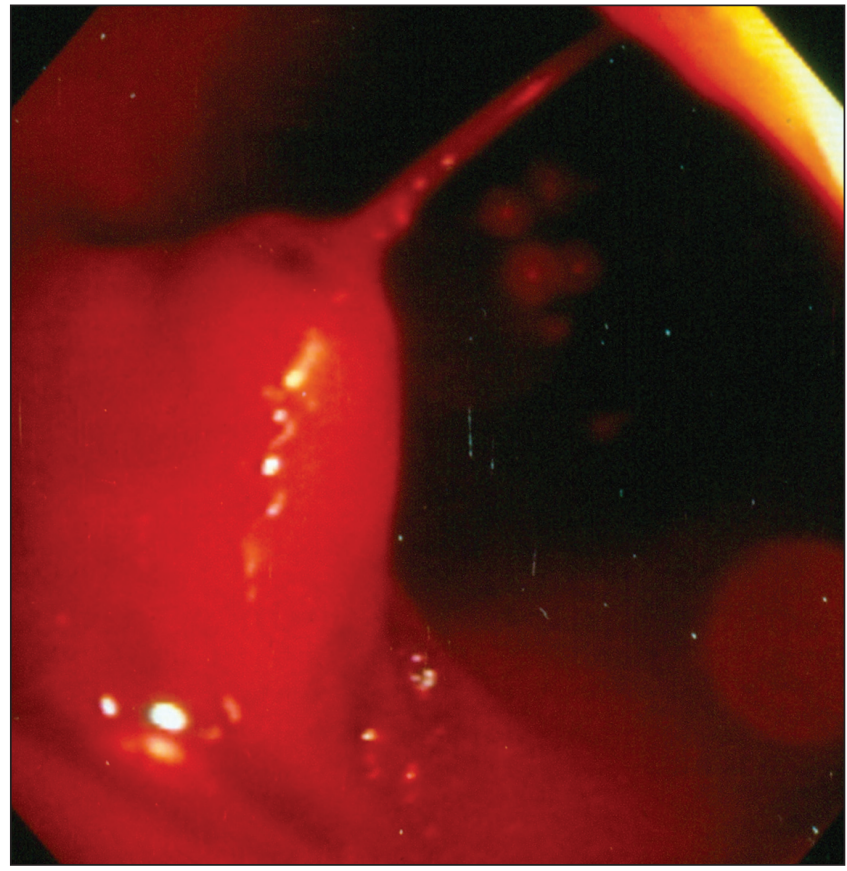

Figure 4) Spurting stalk after a polypectomy in the sigmoid colon

Colonic diverticular bleeding has been reported to be effectively treated by EBL in four patients (40). There were no complications or rebleeding during a 12-month follow-up period.

\section{REFERENCES}

1. Laine L, Cook D. Endoscopic ligation compared with sclerotherapy for treatment of esophageal variceal bleeding. A meta-analysis. Ann Intern Med 1995;123:280-7.

2. Karnam US, Barkin J. Vascular malformations of the small intestine. Curr Treat Options Gastroenterol 2001;4:173-9.

3. Wong RM, Ota S, Katoh A, et al. Endoscopic ligation for non-esophageal variceal upper gastrointestinal hemorrhage. Endoscopy 1998;30:774-7.

4. Abi-Hanna D, Williams S, Gillespie P, Bourke M. Endoscopic band ligation for non-variceal non-ulcer gastrointestinal hemorrhage. Gastrointest Endosc 1998;48:510-4.

5. Junquera F, Brullet E, Campo R, Calvet X, Puig-Diví V, Vergara M. Usefulness of endoscopic band ligation for bleeding small bowel vascular lesions. Gastrointest Endosc 2003;58:274-9.

6. Pointner R, Schwab G, Königsrainer A, Dietze O. Endoscopic treatment of Dieulafoy's disease. Gastroenterology 1988;94:563-6.

7. Parra-Blanco A, Takahashi H, Mendez Jerez PV, et al. Endoscopic management of Dieulafoy lesions of the stomach: A case study of 26 patients. Endoscopy 1997;29:834-9.

8. Schmulewitz N, Baillie J. Dieulafoy lesions: A review of 6 years of experience at a tertiary referral center. Am J Gastroenterol 2001;96:1688-94.

9. Yilmaz M, Ozütemiz O, Karasu Z, et al. Endoscopic injection therapy of bleeding Dieulafoy lesion of the stomach. Hepatogastroenterology 2005;52:1622-5.

10. Sone Y, Kumada T, Toyoda H, Hisanaga Y, Kiriyama S, Tanikawa M. Endoscopic management and follow-up of Dieulafoy lesion in the upper gastrointestinal tract. Endoscopy 2005;37:449-53.

11. Cheng CL, Liu NJ, Lee CS, et al. Endoscopic management of Dieulafoy lesions in acute nonvariceal upper gastrointestinal bleeding. Dig Dis Sci 2004;49:1139-44.

12. Norton ID, Petersen BT, Sorbi D, Balm RK, Alexander GL, Gostout CJ. Management and long-term prognosis of Dieulafoy lesion. Gastrointest Endosc 1999;50:762-7.

13. Brown GR, Harford WV, Jones WF. Endoscopic band ligation of an actively bleeding Dieulafoy lesion. Gastrointest Endosc 1994;40:501-3.

14. Yoshikumi Y, Mashima H, Suzuki J, et al. A case of rectal Dieulafoy's ulcer and successful endoscopic band ligation. Can J Gastroenterol 2006;20:287-90.

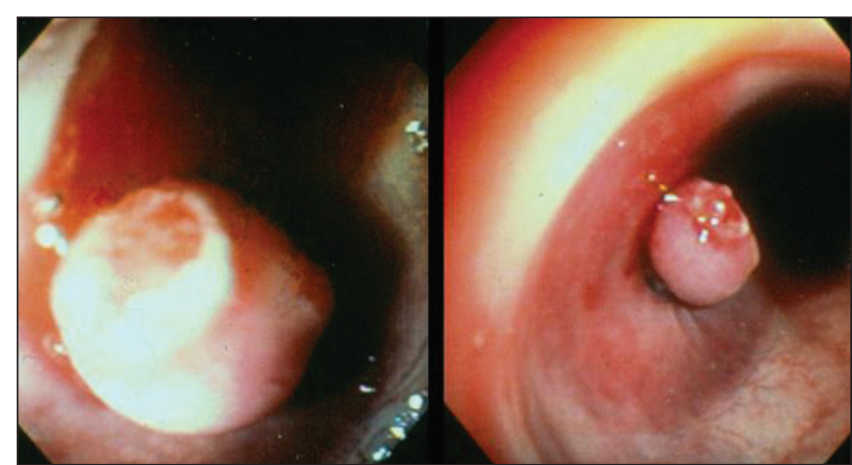

Figure 5) Stalk of polyp ligated with control of bleeding

\section{CONCLUSIONS}

EBL is increasingly being used as a primary therapy for nonvariceal bleeding lesions in the GI tract. It has been shown to be an easy and safe method with a high rate of success. It is at least equally effective as the previous standard methods such as hemoclipping, injection of adrenaline or sclerosants, and thermal therapy. There is more information in patients with vascular malformations, Dieulafoy lesions and MWTs, but recent studies have also shown promising results for the treatment of GAVE and PPB. EBL could be a primary or alternative method for the treatment of nonvariceal bleeding lesions of the GI tract.

15. Hurlstone DP. Successful endoscopic band ligation of duodenal Dieulafoy's lesions. Further large controlled studies required. Scan J Gastroenterol 2002;37:620.

16. Soetikno RM, Piper J, Montes H, Ukomadu C, Carr-Locke DL. Use of endoscopic band ligation to treat a Dieulafoy's lesion of the esophagus. Endoscopy 2000;32:S15.

17. Chen YY, Su WW, Soon MS, Yen HH. Delayed fatal hemorrhage after endoscopic band ligation for gastric Dieulafoy's lesion. Gastrointest Endosc 2005;62:630-2.

18. Mumtaz R, Shaukat M, Ramirez F. Outcomes of endoscopic treatment of gastroduodenal Dieulafoy's lesion with rubber band ligation and thermal/injection therapy. J Clin Gastroenterol 2003;36:310-4.

19. Park CH, Joo YE, Kim HS, Choi SK, Rew JS, Kim SJ. A prospective, randomized trial of endoscopic band ligation versus endoscopic hemoclip placement for bleeding gastric Dieulafoy's lesions. Endoscopy 2004;36:677-81.

20. Myung SJ, Kim HR, Moon YS. Severe Mallory-Weiss tear after endoscopy treated by endoscopic band ligation. Gastrointest Endosc 2000;52:99-101.

21. Gunay K, Cabioglu N, Barbaros U, Taviloglu K, Ertekin C. Endoscopic ligation for patients with actively bleeding MalloryWeiss tears. Surg Endosc 2001;15:1305-7.

22. Park CH, Min SW, Sohn YH, et al. A prospective, randomized trial of endoscopic band ligation vs epinephrine injection for actively bleeding Mallory-Weiss syndrome. Gastrointest Endosc 2004;60:22-7

23. Higuchi N, Akahoshi K, Sumida Y, et al. Endoscopic band ligation therapy for upper gastrointestinal bleeding related to Mallory-Weiss syndrome. Surg Endosc 2006;20:1431-4.

24. Cho YS, Chae HS, Kim HK, et al. Endoscopic band ligation and endoscopic hemoclip placement for patients with Mallory-Weiss syndrome and active bleeding. World J Gastroenterol 2008;14:2080-4.

25. Slivka A, Parsons W, Carr-Locke D. Endoscopic band ligation for treatment of post-polypectomy hemorrhage. Gastrointest Endosc 1994:40:230-2.

26. Smith RE, Doull J. Treatment of colonic post-polypectomy bleeding site by endoscopic band ligation. Gastrointest Endosc 1994;40:511-4. 
27. Pfaffenbach B, Adamek RJ, Wegener M. Endoscopic band ligation for treatment of post-polypectomy bleeding. Z Gastroenterol 1996;34:241-2.

28. Jensen DM, Chaves DM, Grund K. Endoscopic diagnosis and treatment of watermelon stomach. Endoscopy 2004;36:640-7.

29. Ito M, Uchida Y, Kamono S, et al. Clinical comparisons between two subsets of gastric antral vascular ectasia. Gastrointest Endosc 2001;53:764-70.

30. Kovacs TO, Jensen DM. Recent advances in the endoscopic diagnosis and treatment of upper gastrointestinal, small intestinal, and colonic bleeding. Med Clin N Am 2002;86:1319-56.

31. Cugia L, Carta M, Dore MP, et al. The watermelon stomach: Successful treatment by monopolar electrocoagulation and endoscopic injection of polidocanol. J Clin Gastroenterol 2000;31:93-4.

32. Petrini JL, Johnston JH. Heat probe treatment for antral vascular ectasia. Gastrointest Endosc 1989;35:324-8.

33. Kantsevoy SV, Cruz-Correa MR, Vaughn CA, et al. Endoscopic cryotherapy for the treatment of bleeding mucosal vascular lesions of the GI tract: A pilot study. Gastrointest Endosc 2003;57:403-6.
34. Probst A, Scheudbel R, Wienbeck M. Treatment of watermelon stomach (GAVE syndrome) by means of endoscopic argon plasma coagulation (APC): Long-term outcome. Gastroenterology 2001;39:447-52.

35. Chaves DM, Baba ER, Sakai P, et al. The argon beam plasma coagulation (ABPC) for treatment of gastric antral vascular ectasia (watermelon stomach). Endoscopy 1991;31(Suppl 1):E36.

36. Grund KE, Straub T, Farin G. New haemostatic techniques: Argon plasma coagulation. Bailliere's Best Pract Res Clin Gastroenterol 1999;13:67-84.

37. Sinha S, Udawat $\mathrm{H}$, Varma S, et al. Watermelon stomach treated with endoscopic band ligation. Gastrointest Endosc 2006;64:1028-31.

38. Kumar R, Mohindra S, Pruthi HS. Endoscopic band ligation: A novel therapy for bleeding gastric antral vascular ectasia. Endoscopy 2007;39:E56-E57.

39. Nijhawan S, Kumar D, Joshi A, et al. Endoscopic band ligation for non-variceal bleed. Indian J Gastroenterol 2004;23:186-7.

40. Farrell JJ, Graeme-Cook F, Kelsey PB. Treatment of bleeding colonic diverticula by endoscopic band ligation: An in-vivo and ex-vivo pilot study. Endoscopy 2003;35:823-9. 


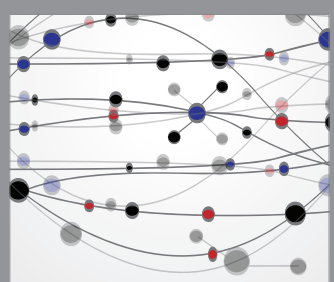

The Scientific World Journal
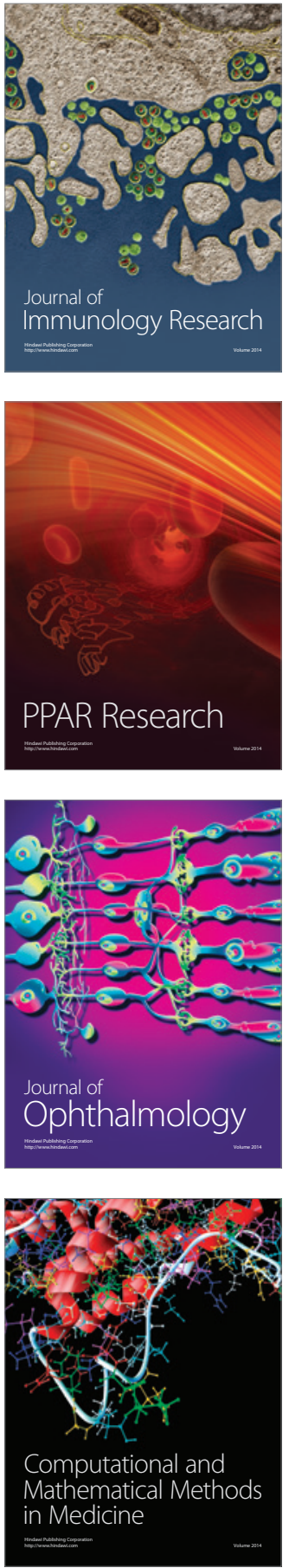

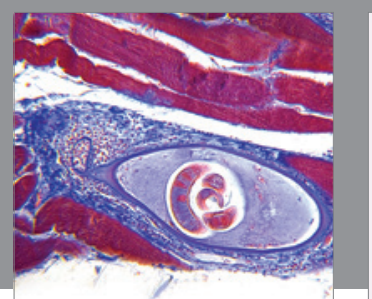

Gastroenterology Research and Practice

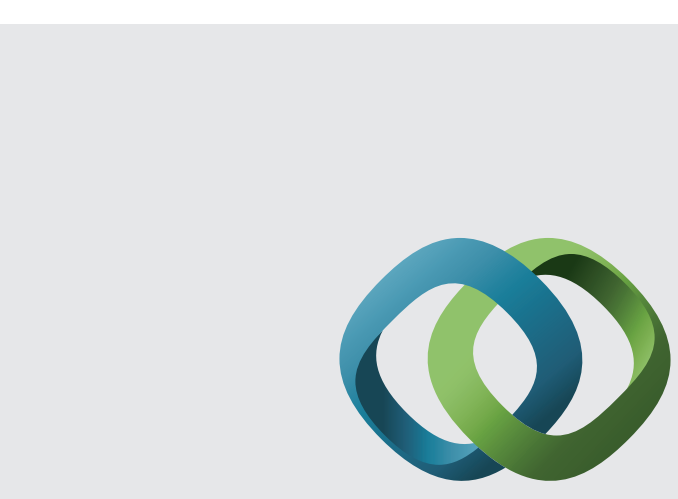

\section{Hindawi}

Submit your manuscripts at

http://www.hindawi.com
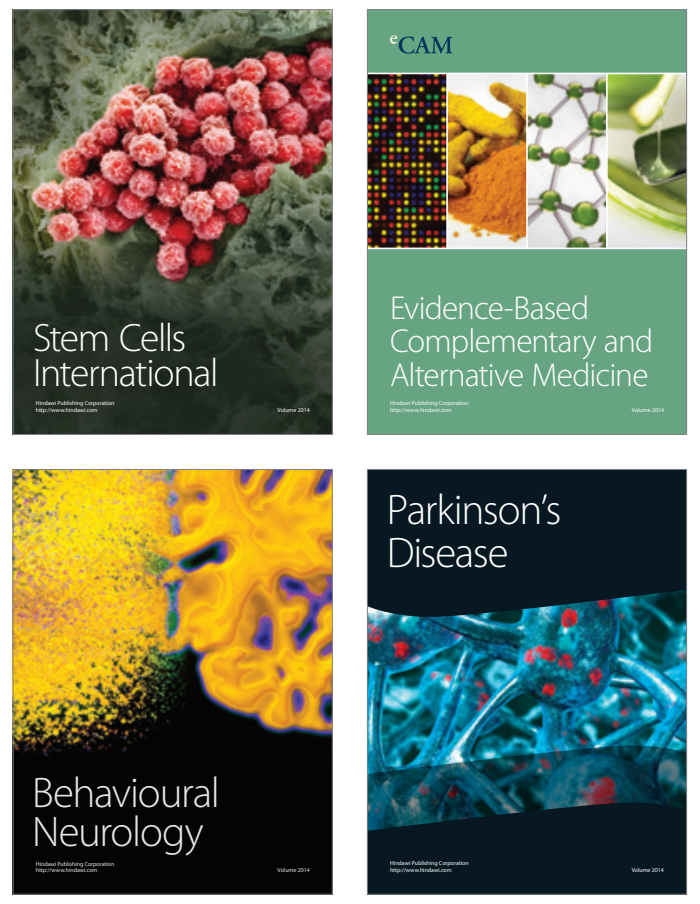
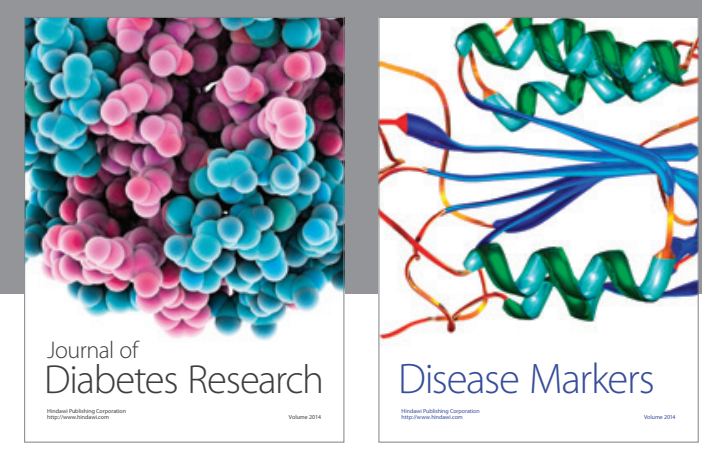

Disease Markers
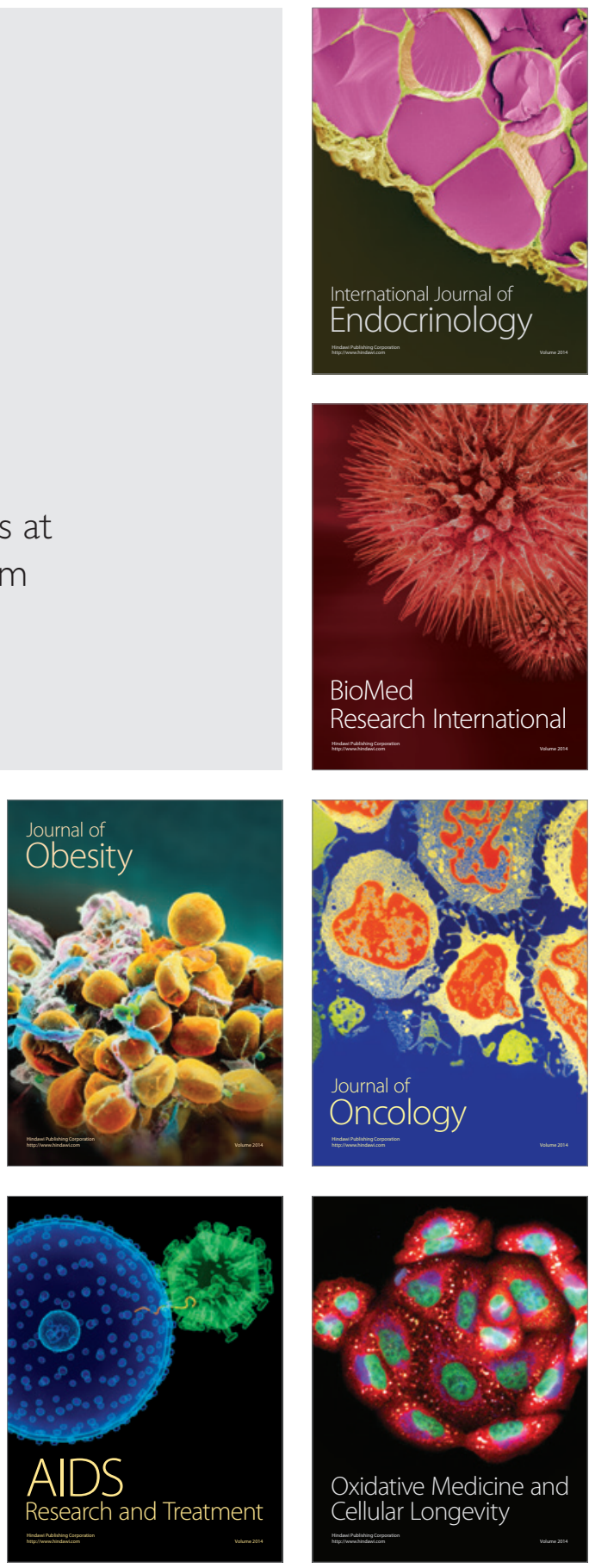